\title{
Outcomes of Excision of Parasagittal Meningiomas
}

\author{
Ahmed Saro*, Momen Mohamed Elma'mon \\ Department of Neurosurgery, Faculty of Medicine, Sohag University, Egypt \\ *Corresponding author: Ahmed Saro, Mobile: +201003911767, E-mail: ahmedsaro33@yahoo.com
}

\begin{abstract}
Background: Meningiomas that have any relation to the superior sagittal sinus are called parasagittal meningiomas. They have an insidious onset and grow gradually and can reach a large size without any manifestations. The surgical management of these tumors is still controversial whether to excise the tumor completely with risks of cerebral infarction and massive brain edema or to excise it gradually with lifting some tumor remains with the risk of tumor recurrence.

Objective: To report our experience with the surgically managed parasagittal meningiomas with analysis of factors that influence the patients' outcome and reporting the complications including tumor recurrence.

Patient and method: A retrospective study was applied on 27 patients (17 females and 10 males) with parasagittal meningiomas in Sohag District between September 2015 and September 2018 with a mean age of $53.5 \pm 2$ years. Preoperative and postoperative data were collected and analyzed.

Results: Out of 27 patients, in 14 of them the sinus was patent, in 9 the sinus was partially occluded, and 4 patients had complete sinus occlusion. The sinus was ligated and excised with the tumor in 11 patients, of those eleven patients, four had venous infarction and three had postoperative massive brain edema. The second group included 16 patients at which, residuals of tumors were left behind with the sinus. Remote follow-up of this group show recurrence in 3 patients.

Conclusion: The outcome of radical resection is favorable whenever possible as the main limiting factor for achieving gross total resection is sinus involvement. However complete excision is crucial to prevent recurrence and many factors share in the success of the surgery. However, the sinus invaded meningiomas should be cautiously managed to prevent postoperative hemodynamic complications.
\end{abstract}

Keywords: Brain edema, Magnetic resonance venography (MRV), Meningiomas, Superior sagittal sinus (sss), Total excision.

\section{INTRODUCTION}

The management of parasagittal meningioma is still a highly controversial issue. The few series reported that there is no agreement about the best option of treatment. While some authors believe that sinus invasion is an absolute contraindication for the total excision (1), other authors see this invasion as a good chance for complete excision especially if the sinus obstruction is complete due to the high collateral circulation $^{(2)}$. On the other hand, many authors considered the subtotal excision is better due to avoidance of major venous complications as venous infarction and massive brain edema with the risk of recurrence ${ }^{(3)}$. The ideal management is to achieve total tumor excision without venous complications ${ }^{(4)}$.

The aim of the present study was to present our experience with the different options of treatment of parasagittal meningiomas and report different complications that occurred in our cases.

\section{PATIENT AND METHOD}

Study type: A retrospective study.

Study design: The study was done in the Neurosurgery Department, Sohag Faculty of Medicine between September 2015 and September 2018. It included 27 patients.

The majority of patients were females (63\%) while males constituted $37 \%$, with ages ranging from 41 to 67 years old.

All patients were subjected to preoperative CT brain, MRI brain, and MRV (magnetic resonance venography). MRV is important to evaluate the degree of sinus patency and to detect the draining cortical veins. Microsurgical resection was done for them.

All the preoperative clinical data, WHO grading, and postoperative complications were gathered and analyzed. Follow-up was done for all patients for about three years (mean follow-up was 2.8 years).

\section{Ethical considerations:}

The study protocol was approved by the Local Ethical Committee of Sohag Faculty of Medicine, under the number 3317/2009. Every patient signed an informed written consent for acceptance of the operation. This work has been carried out in accordance with The Code of Ethics of the World Medical Association (Declaration of Helsinki) for studies involving humans.

\section{Statistical analysis}

Data were analyzed using the statistical package for the social sciences (IBM-SPSS), version 25 (IBMCorporation, Chicago, USA; August 2017). Quantitative data were expressed as mean and standard deviation (SD), while qualitative data were expressed as number and percentage.

\section{RESULTS}

The demographic and clinical manifestations are showin in table 1. Headache, contralateral 
hemiparesis, and seizures were reported in $88.9 \%$, $44.4 \%, 51.9 \%$ respectively.

Table (1): Demographic and clinical data of the studied patients

\begin{tabular}{|l|l|c|}
\hline \multicolumn{2}{|c|}{ Item } & Value \\
\hline \multirow{2}{*}{ Sex } & Males & $10(37.0 \%)$ \\
\cline { 2 - 3 } & Females & $17(63.0 \%)$ \\
\hline Age (years) & Mean \pm SD & $53.5 \pm 8.2$ \\
\hline Follow up (years) & Mean \pm SD & $2.82 \pm 0.20$ \\
\hline Symptoms & Headache & $24(88.9 \%)$ \\
\cline { 2 - 3 } & $\begin{array}{l}\text { Contralateral } \\
\text { hemiparesis }\end{array}$ & $12(44.4 \%)$ \\
\hline
\end{tabular}

Tumor characteristics including tumor location, size, and tumor grades are shown in table 2 .

Table (2): Tumor characteristics in the studied patients

\begin{tabular}{|c|l|c|}
\hline \multirow{2}{*}{$\begin{array}{c}\text { Tumor } \\
\text { location }\end{array}$} & Item & No (\%) \\
\cline { 2 - 3 } & Middle third of the sinus & $11(40.7 \%)$ \\
\cline { 2 - 3 } & Posterior third of the sinus & $4(14.4 \%)$ \\
\hline \multirow{2}{*}{ Tumor } & $<4 \mathrm{~cm}$ & $5(18.5 \%)$ \\
\cline { 2 - 3 } size & $4-6 \mathrm{~cm}$ & $18(66.7 \%)$ \\
\cline { 2 - 3 } & $>6 \mathrm{~cm}$ & $4(11.8 \%)$ \\
\hline \multirow{2}{*}{$\begin{array}{c}\text { WHO } \\
\text { Grading }\end{array}$} & Grade I & $20(74.1 \%)$ \\
\cline { 2 - 3 } & Grade II & $6(22.2 \%)$ \\
\cline { 2 - 3 } & Grade III & $1(3.7 \%)$ \\
\hline
\end{tabular}

The main controlling factor of treatment was the sinus involvement. The major complications were venous infarction with subsequent massive brain edema, which happened in four patients, one of those four died due to progressive infarction (3.7\%), contralateral neurological deficit occurred in (29.6\%) which improved later by physiotherapy. Recurrence occurred in 3 patients with totally excised tumors, all of them treated by Gamma Knife (11.1\%) and they were stable till the writing of this paper. The median time for recurrence was 2.8 years (Table 3 ).

Table (3): Treatment and follow up

\begin{tabular}{|c|c|c|}
\hline & Item & No $(\%)$ \\
\hline Treatment & $\begin{array}{l}\text { Total excision with } \\
\text { sinus ligation }\end{array}$ & $\begin{array}{c}11 \\
(40.7 \%)\end{array}$ \\
\hline & $\begin{array}{l}\text { Total excision with } \\
\text { sinus reconstruction }\end{array}$ & $\begin{array}{c}4 \\
(14.8 \%)\end{array}$ \\
\hline & Near-total excision & $\begin{array}{c}12 \\
(44.4 \%)\end{array}$ \\
\hline Complications & $\begin{array}{l}\text { Venous infarction with } \\
\text { subsequent massive } \\
\text { brain edema }\end{array}$ & $\begin{array}{c}4 \\
(11.8 \%)\end{array}$ \\
\hline & $\begin{array}{l}\text { Contralateral } \\
\text { neurological deficit }\end{array}$ & $\begin{array}{c}8 \\
(29.6 \%)\end{array}$ \\
\hline & Recurrence & $\begin{array}{c}3 \\
(11.1 \%)\end{array}$ \\
\hline
\end{tabular}

\section{DISCUSSION}

Management of parasagittal meningioma is still a highly controversial issue. Authors found that females are affected more than males as reported in Gatterbauer et al. ${ }^{\left({ }^{(5)}\right.}(72 \%)$, Pettersson et al. ${ }^{(6)}(65 \%)$, Caroli et al. ${ }^{(7)}$ (57.6\%), DiMeco et al. ${ }^{(8)}(67.5 \%)$, and $(63 \%)$ in this study. The mean age of patients ranged from 55 years to 57 years which is close to mean age of our study (53.5 years).

Gutterbauer et al. ${ }^{(5)}$ found that the clinical presentation were seizures in (27\%), headache in (23\%), and hemiparesis in $17 \%$ whereas Caroli et al. ${ }^{(7)}$ reported motor deficit in 58\% and seizures in $46 \%$ of their patients ${ }^{(5,7)}$. While in our study we found that $88 \%$ of the patient presented with headache, contralateral hemiparesis, and seizures in $88.9 \%, 44.4 \%, 51.9 \%$ respectively.

As regards the location along with the SSS, most series report affection of the middle third to be the most common followed by the anterior third and lastly the posterior third; 49\%, 37\%, and 14\% in Petterson et al. (6) study, 46\%, 32\%, 21\% in Caroli et al. ${ }^{(7)}$ study, and $45 \%, 41 \%$, and $14 \%$ in our study. The cortical veins that serve as the normal drainage pathway of the brain, as well as those that may offer important collateral drainage, should well be preserved during surgery because when the venous outflow is compromised, venous infarction follows, resulting in brain swelling, hemorrhage, and neuronal death ${ }^{(9)}$.

The best surgical management of meningiomas involving the middle or posterior third of the sagittal sinus has not been established. The anterior third of the superior sagittal sinus, regardless of its patency, can be ligated and divided without causing cerebral damage and neurological deficits ${ }^{(\mathbf{1 0})}$.

Gutterbeuar et al. ${ }^{(5)}$ reported Simpson GI resection in $11 \%$ of their patients, $57 \%$ with Simpson GII, $15 \%$ with GIII, and $17 \%$ with GIV, while these values were $39 \%, 10 \%, 24.5 \%$, and $26.5 \%$ respectively in Petterson et al. ${ }^{(6)}$ and in this current study, Simpson grade I or II with sinus ligation were performed in 11 patients $(40.7 \%)$, the sinus was entered with total tumor excision with sinus reconstruction was performed in 4 (14.9\%) patients while near-total excision was done to 12 patients $(44.4 \%)$.

We found that WHO grade of the meningioma was a type I in $74 \%$, type II in $22 \%$, and type III in $4 \%$, which coincides with many studies that also found that WHO type I is the most common histopathological type. It was $81 \%$ in Gutterbeauer et al. $^{(5)}, 89 \%$ in Petterson et al. ${ }^{(6)}, 80 \%$ in DiMeco et al. ${ }^{(8)}$ and Raza et al. ${ }^{(11)}$.

Raza et al. $^{\left({ }^{(11)}\right.}$ reported major complications included venous thrombosis/infarction (7\%), intraoperative air embolism (1.5\%), and death (1.5\%), also Guttrtbeuar et al. (5), said that surgical complication rates were higher if a sinus resection or opening had been performed (18\% vs $13 \%$ for subtotal resection). DiMeco et $\boldsymbol{a l}^{\left(\mathbf{(}^{8}\right)}$ reported serious complications that included brain swelling (nine 
patients; $8.3 \%$ ) and postoperative hematoma (two patients; $1.85 \%$ ). While in our study, the major complication was venous infarction with subsequent massive brain edema, which occurred in four patients (14.8\%), one of those four died due to progressive infarction $(3.7 \%)$ and contralateral neurological deficit occurred in (29.6\%) which improved later by physiotherapy. Petterson et al. ${ }^{(6)}$ found that (41\%) of patients with WHO type I were still alive at a follow-up of 25 years. And Oscar et al. ${ }^{(\mathbf{1 2})}$ said that The 5-year survival estimates were $93.7 \%$ and $79.3 \%$, and the 10year survival estimates were $79.8 \%$ and $35.3 \%$ for female and male patients, respectively. The survival curve was better for females in most studies ${ }^{(6,12)}$.

Regarding the recurrence rates, Oscar et al. ${ }^{(12)}$ found that the total recurrence rate at follow-up was 32.7\%. While Raza et al. (11) found the long-term outcomes assessed included recurrence (11\%), and DiMeco et al. ${ }^{(8)}$ reported tumors recurred in 15 patients $(13.9 \%)$. This agrees with our study in which, the recurrence occurred in 3 patients with totally excised tumors, all of them treated by Gamma Knife (11.1\%).

Marc and Sindou ${ }^{(13)}$ reported that the relatively low recurrence rate in their study (4\%) favors attempts at complete tumor removal, including the portion invading the sinus. The subgroup of patients without venous reconstruction displayed statistically significant clinical deterioration after surgery compared with the other subgroups.

\section{CONCLUSION}

Radical resection should be performed whenever it is possible to avoid recurrence with meticulous tumor handling to avoid vascular complications. The favorable prognosis occurs with small tumors $<4 \mathrm{~cm}$, total excision, and a low WHO grading. Reconstructive SSS procedures should be safe for the patient with those slow-growing lesions, as small tumor remnants may remain unchanged for several years.

\section{Financial support and sponsorship: Nil.}

\section{Conflict of interest: Nil.}

\section{REFERENCES}

1. Mathiesen $\mathbf{T}$ (2020): Parasagittal meningiomas. Handbook of Clinical Neurology, 170:93-100.

2. Mantovani A, Di Maio S, Ferreira M et al. (2014): Management of meningiomas invading the major dural venous sinuses: operative technique, results, and potential benefit for higher-grade tumors. World Neurosurgery, 82(3-4):455-67.

3. Biroli A, Chiocchetta M, Gerosa M et al. (2012): Surgical treatment of parasagittal and falcine meningiomas of the posterior third. Acta Neurochirurgica, 154(11):1987-95.

4. Magill S, Theodosopoulos P, McDermott M (2016): Resection of falx and parasagittal meningioma: complication avoidance. Journal of Neuro-oncology, 130(2):253-62.

5. Gatterbauer B, Gevsek S, Höftberger R et al. (2017): Multimodal treatment of parasagittal meningiomas: a single-center experience. Journal of Neurosurgery, 127(6):1249-56.

6. Pettersson-Segerlind J, Orrego A, Lönn $\mathrm{S}$ et al. (2011): Long-term 25-year follow-up of surgically treated parasagittal meningiomas. World Neurosurgery, 76(6):564-71.

7. Caroli E, Orlando E, Mastronardi L et al. (2006): Meningiomas infiltrating the superior sagittal sinus: surgical considerations of 328 cases. Neurosurgical Review, 29(3):236-41.

8. DiMeco F, Li K, Casali C et al. (2004): Meningiomas invading the superior sagittal sinus: surgical experience in 108 cases. Neurosurgery, 55(6):1263-72.

9. Richard K (1975): Proceedings: Meningiomas of the left (dominant) temporal region: catamneses (postoperative follow-up). Acta Neurochirurgica, 31(34):282-3.

10. Nowak A, Dziedzic T, Czernicki T et al. (2014): Surgical treatment of parasagittal and falcine meningiomas invading the superior sagittal sinus. Neurologia I Neurochirurgia Polska, 48(3):174-80.

11. Raza S, Gallia G, Brem H et al. (2010): Perioperative and long-term outcomes from the management of parasagittal meningiomas invading the superior sagittal sinus. Neurosurgery, 67(4):885-93.

12. Colli B, Carlotti C, Assirati J et al. (2006): Parasagittal meningiomas: follow-up review. Surgical Neurology, 3:20-27.

13. Marc P, Sindou A (2006): Results of attempted radical tumor removal and venous repair in 100 consecutive meningiomas involving the major dural sinuses. J Neurosurg., 105:514-25. 